\title{
Cross-Border Risks as an Impact Factor for International Fintech Business Models
}

\author{
Helena Skadina* ${ }^{1}$ and Vilnis Veinbergs, ${ }^{2}$ \\ ${ }^{1}$ Turība University, Faculty of Business Administration, Department of Commerce, 68 Graudu Street, \\ Riga, Latvia \\ ${ }^{2}$ Turība University, Faculty of Business Administration, Department of Commerce, 68 Graudu Street, \\ Riga, Latvia
}

\begin{abstract}
.
Research background: Cross-border activities for FinTech companies in several markets bring them completely new opportunities and drive the appetite for new deals, but the complexity of doing business internationally is often underestimated: many risks, which have an influence of business models, can be determined. The emphasis of this research is on those risks that can be brought into particularly correlation with the cross-border activities of a FinTech company and at the same time influence the whole business activity of it.

Purpose of the article: The aim of this research is to find out what kind of risks corresponds to so called cross-border risk-group and is the most common for internationally designed FinTech business models. Additionally, to determine those business model areas, which are influenced by cross-border risks the most and must be created with focus on avoiding, mitigating or sharing these risks.

Methods: To achieve the goal the authors interviewed representatives of different FinTech companies. In these interviews, experts were asked to describe the most significant risks and to assess the importance of them for each business model dimension by using the Likert's scale as well as to explain the dependencies and the consequences of their influence on different business model areas.

Findings \& Value added: The result of this research forms the basis for conclusions about the most significant cross-border risks and their impact on dimensions of a business model as well as makes recommendations possible for those FinTech-enthusiasts who are going to model their FinTech business internationally.
\end{abstract}

Keywords: cross border risks; business model; impact factor; FinTech

JEL Classification: $G 23$; $G 32 ; 047$

\footnotetext{
${ }^{*}$ Corresponding author: helena.skadina@gmail.com
} 


\section{Introduction}

Globalisation is a process which "...accelerates the flow of people, goods, services, capital, energy and information across country borders" [1]. On the one hand globalisation positively influences the business model of an international operating company by making it possible "...to access cheaper labour and material" [2]. On the other hand, reliance on globalized resources makes business managing much more dependent on factors "that are outside of business owner's control" [2]. The benefits for globalized businesses are substantial for investors because "...they involve new ways of doing business, creating strategic and operational challenges and opportunities" [3], the risks are also enormous and "often bring heightened risk and a range of challenges" [4], [5]. In particular, it is very important to be aware of risks while creating a new business model or widening the existing one when company is going to operate internationally: consequences of each risk, that is not timely and qualitatively identified and assessed, and also mitigated, are usually measured in financial outflows. And this aspect must be seen as avoidable for a company with the objective to operate successfully and sustainably.

Business models are "business blueprints used by an organization to create, provide and capture value". [4]. A clear statement of business model enables a company to acquire a robust understanding of what it is seeking to achieve and the associated threats and opportunities [6]. Thanks to modelling, a clear picture of processes, relationships, dependencies and possible risks in the modelled area can be obtained, and used to timely develop alternative scenarios in order to maintain a stable position on the market, to increase the competitiveness of a company or to reduce the identified risks [7]. Preparing the business model enables the company to identify key dependencies that are required for success and to work out success criteria for measuring the status quo.

The aim of this research is to find out what kind of risks corresponds to so called crossborder risk-group and is the most common for internationally designed FinTech business models. Additionally, to determine those business model areas which are influenced by cross-border risks the most and must be created with focus on avoiding or mitigating these risks.

\section{Methods}

Various methods were used in the research: the theoretical part consists of the scientific literature analysis. Semi-structured interviews with 3 FinTech experts (OC, MR, PB), representing the FinTech industry (E-Money Institution (EMI) of Malta with OC on 29.01.2020), short-term lending company (PLK) of Russia with MR on 27.01.2020 and Payment Institution of Great Britain with PB on 26.01.2020), were conducted during the course of the research. The research data was processed by continuous comparative analysis, using open coding, level 2 coding, axial coding and content analysis method with inductive and deductive approach [8]. In interviews, experts were asked to describe the most significant risks focused on the company's cross-border activity and to assess the importance of them for each business model dimension by using the Likert's scale with points 1-5, where 1 - irrelevant; 2 - unimportant; 3 - moderate; 4 - important; 5 - very important. as well as to explain the dependencies and consequences of their influence on different business model areas. The data is presented in the form of diagrams and pictures. The choice of experts was based on the diversity of their expertise $(\mathrm{OC}-10$ years, $\mathrm{PB}-20$ years, MR -4 years). The companies represented by experts are completely different and unrelated to each other. 


\section{Results and Discussions}

There are several advantages, which allow using business models as a basis of undertaking a risk assessment: “...enables risk specialists to partner with the business; adds transparency around the impact of new market challenges" [3].

Until now there is no consistent theoretical approach to the concept of a business model in the literature: business model is a logical and contemplated interplay of company's decisions, business activities and participants which describes the place, time and reason for business [9], the benefits for customers and partners, the ways in which customers and partners benefit [10], the mechanism of service creation and participants in its provision [11], the way in which the benefit translates into profit [9], profit reallocation way [12] and the involvement and placement of technologies to create company value and promote the operational efficiency of the company [13].

The concept "FinTech" has emerged relatively recently and expresses its essence, including "... the provision of financial services through intensive use of the latest technology" [14]. The concept indicates directly the dependence between business and technology as a fundamental element of the company's business model. To make the appropriate business model analysable or to have starting points for creating new or extending the existing business models there are approaches in the literature which provide the overview how business models can be divided into dimensions. Each of the authors who deals with the business model theory gives its own view on business model components [6], [10], [11], [13]. The authors of the research considered the classification of D. Schallmo as the most appropriate, because there are all of the previously written theories combined and latest research results of business model element division included. The business model according to Schallmo consists of firstly developed vision, building the basis for the business model construction as such; of customer dimension, which determines customer segments, channels, that customers have to be achieved and communicated through, and customer relationships to make it possible to get feedback from customers; of benefit dimension, which describes the services for particular customer segments; of value dimension that includes all the resources, skills and competences necessary to produce and provide services and maintain the business model, as well as processes which are appropriate to ensure the effectiveness of the chosen customer channels, communication ways, internal working chains etc.; of partnership dimension with the relevant choice of partners for producing, maintaining and providing services to customers; of financial dimension, answering the questions about generated costs while modelling and doing business, turnover etc.; of management dimension which defines success factors, decision ways, management style, structure and communication [10].

If the company is going to conduct its business internationally, it carries many additional risks which domestic businesses don't. Cross-border business involves exposure to "local economic conditions" [15]. To be able to timely react on these issues and work out alternative business scenarios possible risks related on company's cross-border activities must be timely identified. Timely means that this identification has to occur while modelling business and not only while doing it, because in the last case the company takes a possible finance outflow risk or even a business interruption risk.

The concept of "cross-border risks" describes "the volatility of returns on international investments caused by events associated with a particular country... " [16] It includes country risk, cross-cultural risk, commercial risk and the financial risk [2]. A wide range of 
theoretical approaches are not observed in the literature about the cross-border risks which could be relevant for the FinTech industry. This aspect builds a potential possibility for development of a new theory which could be relevant for FinTech business modelling.

The commercial risk refers to the firm's potential loss or failure from poorly developed or executed business strategies, tactics or procedures. Managers may usually make poor choices in such areas as selection of business partners, timing of market entry, pricing, creation of product features and promotional themes. While such failures also exist in domestic business, the consequences are usually more costly, when they are committed abroad [17], [18]. It is possible, that this risk relates to each of above-mentioned business model dimensions and impacts the business model the most.

The currency risk (also referred to as financial risk) refers to the "risk of adverse fluctuations in exchange rates" [19], [20]. This risk arises because international transactions are often conducted in more than one national currency. Inflation and other harmful economic conditions experienced in one country may have immediate consequences for exchange rates in another [21]. This risk could arise in customer dimension when the national currency of the customers differs from the company's main currency; additionally, the dependence on the right choice of partners must be noticed because FinTech companies cooperate with banks to hold customer money separately and meet the segregation requirements. Doubtless is the relevance of this risk within the finance dimension, because the differences and fluctuations influence the valuation of assets and the financial result at all.

The country risk refers to the potentially adverse effects on company's operations and profitability caused by developments in the political, legal and economic environment in a foreign country [21], [22]. It includes the possibility of foreign government intervention in firms' business activities. For example, governments may restrict access to markets, impose bureaucratic procedures on business transactions and limit the amount of earned income [18]. From the authors point of view this risk significantly affects the business model itself with all the included dimensions. As to dependencies between the dimensions it relates on the whole activity of the company: the question is how to prevent possible risks before arising them and which aspects must be timely analysed or controlled to avoid the worstcase scenario and keep doing business in a chosen country.

The cross-cultural risk refers to a situation where a cultural miscommunication puts some human value at stake. It is posed by differences in language, lifestyles, mind-sets, customs and/or religion and influence the mind-set and work style of employees and the shopping patterns of buyers [18]. The cross-cultural teams are becoming more common. The advantage is the benefit from an increasingly diverse knowledge and new approaches to solving business problems. This aspect relates on the management dimension where team building and cooperation between the employees is relevant issue. But it is also possible that the company faces potential obstacles, when it comes to cultural differences, because there is a set of common norms shared in an appropriate society and are important by modelling customer and partnership dimensions. What is common for the one country, could be very different for a customer or colleague in another. Recognizing and understanding how cross-culture affects the internationally designed business model makes it possible to be aware of misunderstandings and build a set of particular sensitivity, openness, and curiosity in order to help to put everyone at ease.

Based on the information provided by the experts during the interviews, the authors succeeded in creating of so-called sub-risks and their importance for business models and business modelling (Fig. 1). 


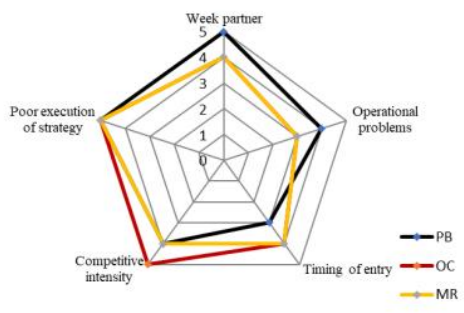

Fig. 1 The impact of commercial risks on the FinTech company's business model

It was possible to define so called sub-risks within the commercial risks that are significant for business models of FinTech companies. These sub-risks are week partnership risks, operational problems, timing of entry, competitive intensity and poor execution of strategy. The assessment of these sub-risks made by the experts made it possible for research authors to point the importance of them. So, for example, the sub-risk of week partnership was mentioned often as one of the risks that influence the partnership dimension. Strategic partnership means the cooperation between different companies. From the customer's perspective, the total quality of the product is co-created by the quality efforts of both supply chain members [23] with the aim to achieve certain economic and strategic goals. It makes a conclusion possible that it influences the financial dimension of the business model as well. Partnership is a very important component because "the partner network influences the value creation of the company" (OC). Knowledge acquired through external network relationships is widely accepted as one of the most important resources for a firm to be innovative [24]. The authors acknowledged a particular relation to the value dimension of a business model by creating a partnership dimension. Strong partnerships in foreign markets help to expand easier because partners are already operating in the market and "know the business culture of the area" (MR) very well. They can "facilitate faster and more efficient expansion" (OC). Companies need to pay close attention to partnerships because it means a "pooling of resources" (OC). Within the framework of cooperation, it is possible to conduct in-depth market research and "share the lessons learned" (PB). The abovementioned made conclusions possible that by modelling the partnership dimension week partnership as a risk could lead to inability of the whole business model of the company. "The level of the competition has to be researched systematically within a company" (OC). The significance of the competition intensity on the foreign market must also be measured and analysed of the company. "We analyse our competitors as if they would be our potential collaborators" (MR) with which "service synergies and long-term market sustainability are possible" (MR). It means that the competitors could be potentially also used as a partner. In case when partnership is week in a particular market this deficit could be compensated by competitors. It affects also the value dimension of a business model as well as the customer dimension because the synergy effect builds a new potential for innovations as it is possible to "develop advantages" (MR) by exploring differences.

Operational problems are one more risk formulated by the experts that is relevant for FinTech business models. It directly relates to the revenue component of the business model. If there are any inadequately controlled and supervised operational activities within the company, it leads to its deterioration and minimizing of revenues. What could be necessary in order to manage the operational problems correctly? The authors suppose that the implementing of an internal risk identification and assessment system could be helpful in order to keep record about the operational problems within the company and to take certain steps towards mitigation of them, to determine decisive preventing actions to avoid 
repetitions of this risk as well as to control both the risk identification process and its management.

As known, FinTech companies work in the digital environment and are closely related to technological innovations. They work with customer data, information and money. Experts admitted the resiliency which must be ensured against disruptive cyber-attack is a very hard task for any company. "Here we have to take all necessary activities to control the information security, create different scenarios, third-party oversight, data protection and fraud authentication processes." (OC). Redesigned process is associated with improved outcomes over time. For the longer term, a more than 1-year post-redesign assessment shows evidence of sustained use of the redesigned work process [25]. On the one hand these are activities which protect the company from possible losses; on the other hand, technological solutions have to be developed while creation of business model in terms of service provision, customer communication, partnership implementing as well in terms of the control and management of the revenues related on the company's activities while the business model is working. This aspect directly affects the speed of provided services as well as the time of entry in a new market. The authors suppose that the technological aspect must be implemented in the modelling process as soon as it is possible and combined with the planning and analysing of possible partnerships and cooperation's because technology is a very expensive position in the business model that influence the financial dimension as well and the aim of the company could be to use partnerships for getting existing technologies and adapting them to the needs of a company. This way could be seen as appropriate way for minimizing the costs of used and implemented technologies.

To sum the aforementioned up the authors conclude that there are risks within the scope of commercial risks that directly correspond to the company's cross-border activities and can be called as cross-border risks that influence the FinTech company's business models by doing business internationally. There are particular dependences acknowledged between the risks and affected business model elements. By ignoring the one aspect it immediately affects the other. In this context the conclusion is possible the responsibility of management in terms of creating a strategical approach by modelling business is highly important. Management is considered "the single most powerful individual whose attitude is likely to influence the organization's overall risk preference" [26], [27]. Such mechanisms as risk identification system are also a result of the researched influence of commercial risks, because the consequences that company could face in case of not identified and unmanaged operational risks could lead to revenue outflow and negatively affect the financial success of the current business model. By assessing the impact of cross-border risks related to crosscultural and financial aspect, an almost complete consensus among experts could be concluded (Fig. 2, 3).

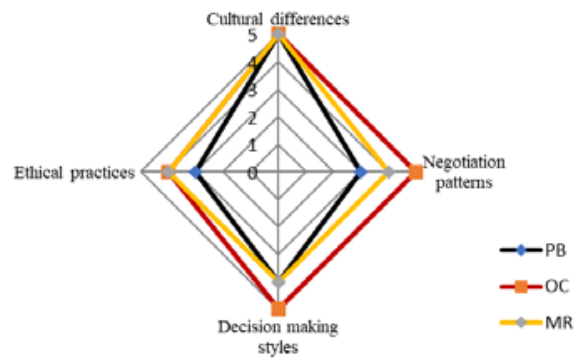

Fig. 2. The impact of cross-cultural risks on the FinTech Company's business model

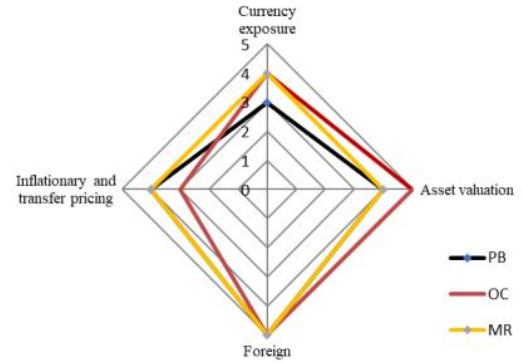

Fig. 3 The impact of financial risks on the FinTech Company's business model 
It was possible to build the next set of cross-border risks within the cross-cultural risk scope based on interviews with above mentioned experts. These are cultural differences, negotiation patters, decision making styles and ethical practices in a foreign market which must be properly analysed and included as influence factors in the process of a FinTech business modelling.

Cross-cultural aspects are one of the key components which characterises the society within one country's borders or outside of it. It means that the role of the social-cultural factors is of particular importance in international business as well. Differences in behaviour, non-verbal as well as paralinguistic means of business communication is extremely important for a successful cooperation. It helps to "understand the intentions and aspirations" (OC) of the business communication partner; knowledge of behavioural features and non-verbal signals contributes to the fact that the "participants of the communication influence each other in the necessary context" (PB). The correctly chosen tactics of behaviour will favourably "affect the reputation and attitude" (PB).

As a result, it is important to consider their "ways of thinking" (MR), mentality, worldview, "value system" (PB) and follow certain rules. The future of decisions largely depends on the properly prepared and conducted business negotiations. Of course, it is necessary to take into account "some national peculiarities of business communication and familiarize the manager with them" (OC). Every country and every nation have its own traditions and customs of business communication and business ethics.

Additionally, the authors identified a number of shortcomings that were considered to be highlighted here: "poor knowledge of foreign languages" (OC), "general constraint during business negotiations, lack of knowledge of their own history" (MR) and its relationship with world history, "low general culture and lack of discussion culture" (OC), "lack of rhetoric knowledge" (PB), "inability to perceive the problem" (MR), "objective information is replaced by subjective views" (PB).

The aforementioned enables to draw certain conclusions in context of the business modelling in FinTech companies: effective communication is essential to the success of a business venture, but it is particularly critical when there is a real risk of the so-called message which is "lost in translation". In almost all internationally operating companies, English is the business language, but more than just the spoken language, is its transmission important. Regarding the modelling process it is also important how messages are conveyed within the team, in particular in an international one. One miscommunicated message could lead to misunderstanding of the process, task or issue. In this context the non-verbal communication between cultures can be equally crucial for the internationally operating company because failed targeting of customers could lead to interrupting of the company's activity in the current market. What does it mean for managers of the company? How to prevent this miscommunication risk? The authors suggest that there would be team building activities in place which help to build a like-minded employee. Further it is possible to recognize that the role as well as the attitude of company's employees would be very important for the value creation dimension. The business model is not just a competence of the company management, but a role-playing game in which all employees are involved. As a result, the company must be dedicated to prepare its employees for the challenges and opportunities of working across borders and cultures. There are information flows, courses, meetings, training and all kinds of activities helpful that lead to the understanding of an internationally conducted business modelling and working with it. It means additional costs for the company that it has to expect for preparing employees. Of course, it directly affects the financial dimension of the business model.

The impact of these risks on business models is very pronounced in terms of foreign taxation and asset valuation. In particular, the taxation system is of importance, if the 
company works in countries outside the EU's economic area, then the depreciation of the currency could lead to deterioration of the company's financial situation. By operating outside a single currency area and working with different currencies, a company must make provisions for "currency risk mitigation and development of crisis scenarios" (MR), "capital adequacy calculation intensity" (OC) and constitution of reserves. The business model has to be considered in relation to the sufficient diversification of the currency portfolio in order to balance currency risks. Every action that needs to be taken to reach the goal costs the company money. Any improper activity creates additional costs for the company. The amount of investment is always limited and slow preparation of the model for the new market entrance could mean a loss of this market for a company. In view of the above, when modelling business, especially when planning financial flows, potential financial risks arising from taxes and currency fluctuations, the management of the company should include an assessment of these aspects before acquiring a new market and even before the deciding about the entry. By assessing the above-mentioned risks, management of the company could change, optimize the model and develop alternative scenarios into desired direction, thus avoid the possibility of the risk occurrence at all.

And the last set of cross-border risks consists of a risk of bureaucracy, lack of legal safeguards for intellectual property rights, legislation that is unfavourable to foreign companies, possible economic failures and mismanagement as well as social and political unrest and instability (Fig. 4).

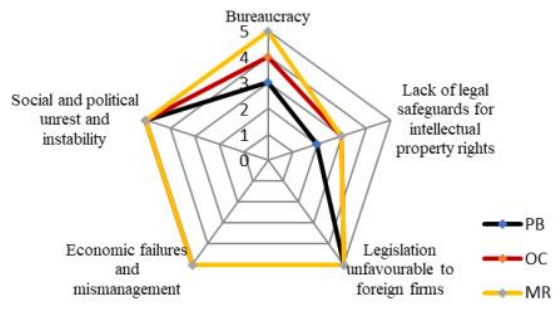

Fig. 4 The impact of country risks on the FinTech Company's business model

When it comes to unrest "people's thoughts are focused on them and not on the services the company offers" (MR). It means that the choice of the country for a business must be evaluated for political stability and unrest reasons before the business is planned in this area. As for the economic failure, experts clearly point out that while planning and preparing a business model, a number of economic determinants must be tested and diagnosed because "economic processes in the country determine business success" (OC). On the one hand, "it is very interesting to work in countries where the level of economic development is not as high as in the CIS countries" (MR), because in these countries the potential for development is enormous. On the other hand, "the company balances in circumstances that carry higher risk of failure" (MR).

\section{Conclusions}

Before entering a new market, the company has to examine: what partnerships are available on this market, what and how partners from other markets could be attracted and be interested to expand together with the company. This way makes partnership also of competitors possible and provides the chance to cooperate for a long time.

Operational problems directly relate to the revenue component of the business model. If 
there are any inadequately controlled and supervised operational activities within the company, it leads to its deterioration and minimizing of revenues.

Effective communication is essential to the success of a business venture, but it is particularly critical when there is a real risk of the so-called message which is "lost in translation." It finally could end in a conflict situation within the company and standstill of work.

By operating outside a single currency area and working with different currencies, a company must make provisions for currency risk mitigation and development of crisis scenarios, capital adequacy calculation intensity and constitution of reserves.

The choice of the country for doing business must be evaluated for political stability and unrest reasons before the business is planned in this area. Political stability, legislation framework and attitudes towards newcomers from other countries must be taken into account by every company that is going to do international cross-border activities.

\section{References}

1. Fritz, V. (2014). The Risks of Conducting Business Internationally. Retrieved from: http://www.vonyaglobal.com/internal-audit/knowledge/the-risks-of-conductingbusiness-internationally/.

2. Trinh, V. Q., Aljughaiman, A., \& Cao, N. D. (2020). Fetching better deals from creditors: Board busyness, agency relationships and the bank cost of debt. International Review of Financial Analysis, 69, 101472.

3. Allen, F. (2011). Cross-border banking in Europe: implications for financial stability and macroeconomic policies. CEPR.

4. Papadopoulos, Ph. (2016). Identification Framework for Business Model Risks, OPENRISKWHITEPAPER, 2-14.

5. Gonzalez-Paramo, J. M. (2006). Cross-border banking in the EU: developments and emerging policy issues. ECONOMIC AND FINANCIAL REVIEW-EUROPEAN ECONOMICS AND FINANCIAL CENTRE, 13(4), 187.

6. Wirtz, B. W. (2011). Business model management. Design-InstrumenteErfolgsfaktoren von Geschäftsmodellen, 2.

7. Skapa, S., \& Novotna, V. (2018). Solving microeconomic model using methods of functional analysis. Economic Computation and Economic Cybernetics Studies and Research, 52, 41-43.

8. Martinsone, K., Pipere, A., Kamerade D. (2016). "Petniecība. Teorija un prakse": Research. Theory and praxis, Riga, 375.

9. Mitchell, D., \& Coles, C. (2003). The ultimate competitive advantage of continuing business model innovation. Journal of Business Strategy, 24(5), 15-21.

10. Schallmo, D. (2013). Geschäftsmodelle erfolgreich entwickeln und implementieren. Berlin, Heidelberg: Springer Berlin Heidelberg.

11. Gassmann, O., Frankenberger, K., \& Csik, M. (2013). Geschäftsmodelle entwickeln: 55 innovative Konzepte mit dem St. Galler business model navigator, München.

12. Bieger, T., \& Reinhold, S. (2011). Das wertbasierte Geschäftsmodell-ein aktualisierter Strukturierungsansatz. In Innovative Geschäftsmodelle. Springer, Berlin, Heidelberg, $13-70$. 
13. Matzler, K., Bailom, F., \& von den Eichen, S. F. (2016). Digital Disruption: Wie Sie Ihr Unternehmen auf das digitale Zeitalter vorbereiten. Vahlen. Kindle Edition, 964972.

14. Takats, E. (2010). Cross-border bank lending to emerging market economies. The Global Crisis and Financial Intermediation in Emerging Market Economies, 11-29.

15. Cameron, S. (2016). Legal Aspects of Cross Border Transactions: Trends, Challenges and Opportunities. Harward Business Revew, 3-8.

16. Poghosyan, T. (2020). How effective is macroprudential policy? Evidence from lending restriction measures in EU countries. Journal of Housing Economics, 49, 101694.

17. El Fotouh, H.A. (2016). Cross-border Compliance. Retrieved from: https://www.linkedin.com/pulse/challenges-cross-border-compliance-hany-abou-elfotouh.

18. Badarau, C., Carias, M., \& Figuet, J. M. (2020). Cross-border spillovers of macroprudential policy in the Euro area. The Quarterly Review of Economics and Finance, 77, 1-13.

19. Nasdaq. Retrieved from: https://www.nasdaq.com/investing/glossary/c/cross-borderrisk.

20. Shepherd, N. G., Mooi, E. A., Elbanna, S., \& Rudd, J. M. (2020). Deciding Fast: Examining the Relationship between Strategic Decision Speed and Decision Quality across Multiple Environmental Contexts. European Management Review, 1-22.

21. Li, L., \& Zhou, H. (2020). A survey of blockchain with applications in maritime and shipping industry. Information Systems and e-Business Management, 1-19.

22. Ramos, H. P., \& Righi, M. B. (2020). Liquidity, implied volatility and tail risk: A comparison of liquidity measures. International Review of Financial Analysis, 69, 101463.

23. Avinadav, T., Chernonog, T., Fruchter, G. E., \& Prasad, A. (2020). Contract Design when Quality is Co-Created in a Supply Chain. European Journal of Operational Research, 286(3), 908-918.

24. Binder, P. (2020). Impacts of network relationships on absorptive capacity in the context of innovation. The Service Industries Journal, 40(13-14), 974-1002.

25. Anand, G., Chandrasekaran, A., \& Sharma, L. (2020). Sustainable process improvements: Evidence from intervention- based research. Journal of Operations Management.

26. Liu, L., Le, H., \& Thompson, S. (2020). CEO overconfidence and bank systemic risk: Evidence from US bank holding companies. International Journal of Finance \& Economics.

27. Hutchinson, M. C., \& O'Brien, J. (2020). Time series momentum and macroeconomic risk. International Review of Financial Analysis, 69, 101469. 